\begin{abstract}
The first aim of this cross-sectional study was to examine the relationships between adolescents' physical self-perceptions (physical condition, sport competence, physical attractiveness, physical strength) and grade in Physical Education (PE). The second aim was to investigate the potential indirect effect of PE test anxiety variables (worry, self-focus, bodily symptoms, somatic tension, perceived control) on the relationships between physical self-perceptions and grade in PE. French adolescent students $(N=412 ; 225$ girls $)$ completed scales assessing physical self-perceptions and PE test anxiety. The results highlighted that grade in PE was positively predicted by sport competence, somatic tension, and perceived control, and negatively predicted by bodily symptoms in PE. The results also showed that bodily symptoms have a significant negative indirect effect on the relationships between perceived sport competence and grade in PE, and between physical strength and grade in PE. A significant indirect effect of somatic tension on the relationship between sport competence and grade in PE has also been found.
\end{abstract}

Keywords: anxiety; self-concept; evaluation; adolescence; school; education. 


\section{Relationship Between Perceived Physical Self-Concept and Grade in Physical Education: The Mediating Role of Test Anxiety}

Nicolas Mascret ${ }^{\mathrm{a} *}$, Olivier Rey $^{\mathrm{a}}$, Sarah Danthony $^{\mathrm{a}}, \&$ Christophe Maïano $^{\mathrm{b}}$

${ }^{a}$ Aix Marseille Univ, CNRS, ISM, Marseille, France

${ }^{b}$ Cyberpsychology Laboratory, Department of Psychoeducation and Psychology, Université du Québec en Outaouais (UQO), Canada

*Corresponding author

Nicolas Mascret

Institute of Movement Science, 163 avenue de Luminy, Case 910, 13288 Marseille cedex 9, France

Email: nicolas.mascret@univ-amu.fr

Date of submission: July 12, 2021

The author reports no conflicts of interest.

\section{Acknowledgements}

The authors want to warmly thanks Alexandre J.S. Morin for invaluable advice during the revision of the manuscript. 


\title{
Relationship Between Perceived Physical Self-Concept and Grade in Physical Education: The Mediating Role of Test Anxiety
}

\begin{abstract}
Introduction
Self-concept is an individual's self-perception constructed through experience with interpretations of one's environment (Marsh, Trautwein, Lüdtke, Koller, \& Baumert, 2006). It may be considered a mediating variable that facilitates the achievement of desired outcomes such as physical skills and physical condition and adherence to physical activity (Marsh, 2002). Self-concept is often specified, such as the academic self-concept, which is an individual's self-perceived ability in academic situations (Raufelder \& Ringeisen, 2016). Another kind of self-concept is of interest in studies focusing on sport and Physical Education (PE) domains, namely the physical self-concept.
\end{abstract}

The physical self-concept (i.e., the individual's self-assessment of his/her own physical abilities) is most directly related to the general self-concept (Biddle \& Goudas, 1994), particularly among adolescents (Harter, 1990). The physical self-concept may be considered in PE a central psychological construct because of its situation at the interface of the individual's self-concept and the social and/or physical environment in which it operates (Fox, 2000). The physical self-concept has been developed in the physical self-perception profile by Fox and Corbin (1989). In the physical self-concept, two levels of hierarchy can be distinguished. At the first level, there is "Physical Self Worth". Its development, which is itself influenced by physical practice, would contribute to the promotion of overall selfconcept (Biddle \& Goudas, 1994) and a certain level of self-confidence that would mediate the maintenance of physical activity and/or sport. The second level of the hierarchy, which is 
more unstable, includes most physical abilities: perceived physical condition (i.e., perception of one's own level of fitness, which conditions one's ability to maintain prolonged effort), perceived physical strength (i.e., explosiveness, muscular power that determines comfort in situations where strength is required), perceived sport competence (i.e., perception of motor skills in a physical activity and sport, but also ability to learn new gestures), and perceived attractive body (i.e., perception of one's appearance in the eyes of others, and the selfperceived attractiveness of one's own body). In PE, students encounter a huge range of experiences in different activities during their school years, which could impact on the perception of their physical abilities and their body attractiveness, but also their performance in PE.

\section{Physical Self-Concept and Performance in Sport and PE}

In general, academic self-concept is consistently related to academic achievement (Marsh \& Craven, 2006). The pattern is similar for domain-specific studies. For instance, math self-concept is positively related to math achievement (e.g., Arens, Marsh, Craven, Yeung, Randhawa, \& Hasselhorn, 2016). Other studies have also examined the relationship between physical self-concept and different kinds of performance in sport and PE. In a study conducted with elite athletes, Marsh and Perry (2005) showed that swimmers' physical selfconcept was a predictor of their swimming performance in two international events. With a less specific population than high-level athletes, many studies have highlighted that physical self-concept is usually known to be closely associated with the time and effort engaged in practice of physical activities and sports (Dapp \& Roebers, 2019; for a review, see Marsh, 2002). 
In the specific context of PE, Peart, Marsh, and Richards (2005) found a positive association between students' physical self-concept, skill development, and motor learning. More specifically, another study focused on the reciprocal model of gymnastics self-concept and performance in PE (Marsh, Chanal, \& Sarrazin, 2006). This study was conducted among a sample of 376 French adolescent students involved in a 10-week gymnastics program in PE measured during the first and the last session of the program. Findings showed that gymnastics performance and gymnastics self-concept were reciprocally related across time. The principal results showed that more positive levels of prior self-concept led to higher subsequent levels of gymnastics performance than could be explained by prior levels of gymnastics performance. However, higher levels of prior gymnastics performance also led to higher levels of subsequent gymnastics self-concept than could be explained by prior levels of gymnastics self-concept. These results confirmed the first results found by Chanal, Marsh, Sarrazin, and Bois (2005). More recently, Lohbeck, von Keitz, Hohmann, and Daseking (2021) highlighted that the physical self-concept of 7-8-year-old schoolchildren was significantly and positively related to physical performance assessed during tests conducted in PE courses. But in the two studies conducted in gymnastics (Chanal et al., 2005; Marsh et al., 2006), performance was not assessed by the PE teachers, but by three independent expert judges through videotapes of students performing a standardized gymnastics test. In Lohbeck et al.'s study, students' performance was assessed by ten physical tests (e.g., 20-m sprint, push-ups, ball throw) which are not directly in relation to what has been specifically studied in PE. In these studies, students' performance was not assessed under ecological conditions that students usually encounter in PE lessons, such as grades given by PE teachers. But grades have not been used hitherto to examine the relationships between physical self-concept and 
this kind of performance in PE, while educational studies mainly use grades obtained by students to assess performance in academic subjects (Putwain, Connors, \& Symes, 2010). This was the first aim of the present study. In numerous studies, other variables, such as test anxiety, have been examined as mediators between self-concept and performance in the school context, which was the second aim of the present study.

\section{Test Anxiety as a Mediator of the Relationship Between Perceived Physical Self-Concept and Grade in PE}

PE may be considered stress-inducing for many reasons, such as the social pressure induced by the motor task performed in front of classmates and teachers (Liukkonen, Barkoukis, Watt, \& Jaakkola, 2010) and the fact that the result is immediately available and known to all (Barkoukis, Tsorbatzoudis, Grouios, \& Rodafinos, 2005). Anxiety in PE concerns everyone: both low- and high-skilled students are confronted with it (Liukkonnen et al., 2010). Anxiety may also impair their performance, in particular due to the negative role played by anxiety on the degree to which individuals are able to control their movements in perceptual-motor performance (Nieuwenhuys \& Oudejans, 2017). In the real-life PE context, assessing the control of the students' movement or their gaze behavior (Nieuwenhuys \& Oudejans, 2017) is often very complicated and requires particular equipment. Consequently, the final outcome has mostly been used in PE as a performance measure, which may be represented by a quantitative result (e.g., the running time, the distance of a long jump) or a grade given by the PE teacher. The study of anxiety-performance relationships in PE has provided mixed results. For example, Barkoukis et al. (2005) showed that anxiety negatively predicted the performance of two track and field tasks in PE (triple jump and shot put), but anxiety was not always detrimental for students' performance in PE by managing their 
anxiety as motivation. Consequently, anxiety-performance relationships need to be further investigated in the PE context for a better understanding. But anxiety can take different forms in this school subject.

A specific form of anxiety, namely test anxiety, may occur in an educational context during tests or examinations which are considered threatening. In similar fashion to the test anxiety experienced in all school subjects (e.g., Putwain et al., 2010), test anxiety in PE is defined as a multidimensional attribute with five components (Danthony, Mascret, \& Cury, 2019). Four components were negatively toned: worry (i.e., fear of failure), self-focus (i.e., what might other students say or think about my performance during the PE test?), bodily symptoms (e.g., breathing difficulty, headache), and somatic tension (e.g., feeling nervous). The cognitive dimension of test anxiety was represented by worry and self-focus, and the affective-physiological dimension by bodily symptoms and somatic tension. The fifth component of PE test anxiety was perceived control (Cheng, Hardy, \& Markland, 2009). It represented the capacity to cope and to attain the purpose of the task under pressure (Cheng et al., 2009; Mascret, Danthony, \& Cury, 2019). In contrast to the cognitive and affectivephysiological dimensions of PE test anxiety, perceived control indicated a regulatory and positively-toned dimension of PE test anxiety (Danthony et al., 2019). Although PE is a school subject that confronts students with many different activities, the present study investigated PE test anxiety in general, independently of the physical activities taught and of the number of evaluations experienced by the students. Indeed, test anxiety in PE is considered a psychological trait, which is therefore rather stable and related to the school subject itself (Danthony et al., 2019). Investigating test anxiety may be relevant in the PE 
context to better explain why some students fail when they have to take an examination or assessment in that school subject.

An unequivocal pattern of results was found concerning the negative relations among the different factors of general test anxiety and examination performance, especially the worry dimension, which is the strongest negative predictor of academic performance, often represented by the grades obtained by the students (e.g., Putwain et al., 2010). The question then arose of whether the pattern was similar in the PE context, because recent studies (e.g., Danthony et al., 2019; Mascret et al., 2019) have shown that PE test anxiety has similar relationships with other constructs than those in the general test anxiety literature, but also specific relationships. Because test anxiety was also studied in relation with self-concept, one of the aims of the study was to examine the indirect effects of the five components of PE test anxiety between physical self-concept and performance in PE.

In the general test anxiety literature, academic self-concept was studied as an antecedent of test anxiety. The results have highlighted that academic self-concept negatively predicted test anxiety or some components of test anxiety (e.g., Raufelder \& Ringeisen, 2016). Academic self-concept was often found to be a significant positive predictor of academic performance (e.g., Choi, 2005). In the general test anxiety literature, test anxiety was also studied as a mediator between academic self-concept and academic performance. For example, worry was identified as a mediator between academic self-concept and school grades of gifted students (Zeidner \& Schleyer, 1999) and test anxiety mediated the relationships between academic self-concept and academic performance of nursing students (Khalaila, 2015). But Marsh (2006) recommended using more subject-specific measures of self-concept to increase its explanatory power, because a student may have a high academic 
self-concept in mathematics but a low one in English. Moreover, a perceived anxiety may be induced for students through the presentation of the physical self in circumstances in which their physiques are perceived as being evaluated by teachers or peers (Hart, Leary, \& Rejeski, 1989), especially for older students and boys (Hagger, Burn, Mutton, \& Brindley, 2008), and may finally influence students' performance. These results suggest that physical self-concept may be related to anxiety experienced by students during academic evaluations, namely test anxiety. But the precise relationships between physical self-concept, test anxiety, and performance have not yet been examined in the PE context. Consequently, studying the potential indirect effect of PE test anxiety between physical self-concept and performance in PE seems worthy of interest to better explain why some students succeed while others fail in PE evaluations, leading to good or bad grades in this school subject.

\section{The Present Study}

This study pursued two objectives. The first objective was to investigate, among adolescents, the relationships between perceived physical condition, sport competence, physical attractiveness, physical strength, and grade in PE. It was hypothesized that high levels of perceived physical condition, sport competence, body attractiveness, and physical strength would be related to higher grade in PE.

The second and main objective was to investigate the possible indirect effect of PE test anxiety variables in the relation between physical self-concept variables and grade in PE. To examine this objective, the model presented in Figure 1 was used. In this model, the full arrows represent a fully mediated (FM) model. More specifically, it was hypothesized that in adolescents: (a) higher levels of perceived physical condition (Paths A1-A5), sport competence (Paths A6-A10), physical attractiveness (Paths A11-A15), and physical strength 
(Paths A16-A20) would be associated with lower levels of worry, self-focus, bodily symptoms, and somatic tension, and higher levels of perceived control; and (b) that lower levels of worry (B1), self-focus (B2), bodily symptoms (B3), and somatic tension (B4), and higher levels of perceived control (B5) would be associated with higher grade in PE.

In addition, as illustrated in Figure 1, a partial mediation (PM) model was added to examine the direct relationships between perceived physical condition (A21), sport competence (A22), physical attractiveness (A23), physical strength (A24), and grade in PE. More specifically, this model made it possible to test whether the direct relationships between physical self-concept variables and grade in PE were significant or not when the mediators were considered. Finally, given that the present study included a mixed-sex and -age sample of adolescents, the roles played by these variables were controlled for in the model as illustrated by the dotted lines in Figure 1 .

\section{Method}

\section{Participants and Procedure}

A total of 412 students (187 boys, 225 girls, $\left.M_{\mathrm{age}}=13.90, S D=1.13\right)$ from French collèges (ages 12-15, 356 students, 51.12\% girls) and lycées (ages 15-19, 56 students, 76.79\% girls) voluntarily and anonymously participated in the study. Participants were recruited through their PE teachers who volunteered their students to participate, while ensuring that schools' socio-demographic profiles and schools' results on national examinations showed diversity. The present study was completely independent of the course grade. The study was first approved by the Chief Education Officer, the schools' principals, and the students' parents who gave their informed consent. The study met the requirements of the ethical committee of the first author's university and of the Commission Nationale de l'Informatique 
et des Libertés (no. 2004-801). French students have three to four hours of PE per week in collège and two hours per week in lycée. PE examinations occur between three and eight times per year and grades obtained in PE contribute to and diploma. At the beginning of PE lessons, the two first authors of the study supervised the procedure, which lasted about ten minutes. Students completed the questionnaires individually. The students were assured that the study was totally anonymous and would not influence their course grade. No evaluations, tests, or examinations were conducted on the day of completion of questionnaires.

Theoretically, demonstrating a task in front of peers is not considered a task that specifically causes test anxiety, because studying PE test anxiety only focuses on evaluative tasks at the end of the learning process which explicitly lead to a grade (Danthony et al., 2019). When this grade is directly involved in the awarding of a diploma, the term 'test' or 'examination' is used, whereas if it is not involved, the term 'evaluation' is used instead. In the present study, these terms are used interchangeably because in all three cases these evaluative tasks lead to PE test anxiety.

\section{Measures}

\section{Physical Self-Concept}

Adolescents" perceived physical condition (e.g., "I think I could run for a long time without tiring”), sport competence (e.g., "I find that I'm good in all sports"), physical attractiveness (e.g., "I have a nice body to look at"), and physical strength (e.g., "I would be good at exercises that require strength") were measured using the French version of the Short Physical Self-Inventory (PSI-S; Maïano et al., 2008; Morin \& Maïano, 2011). As recently recommended by Morin et al. (2018), the PSI-S version with only positively worded items 
was used. Each subscale comprised three items that were rated by the adolescents using a sixpoint response scale ranging from not at all (1) to entirely (6).

\section{PE Test Anxiety}

PE test anxiety was assessed with the Revised Test Anxiety and Regulatory dimension of anxiety in PE scale (RTAR-PE; Danthony et al., 2019), validated in French. Participants responded on a 1 (almost never) to 4 (almost always) scale assessing five variables: worry (e.g. "During PE tests, I often think about how difficult it is"), self-focus (e.g. "During PE tests, I think that other students may criticize my performance”), bodily symptoms (e.g. “During PE tests, my muscles are tighter than during PE lessons"), somatic tension (e.g. “During PE tests, I feel more tense than during PE lessons”), and perceived control (e.g. “During PE tests, I believe in my capacity to get a good grade”).

\section{PE Performance}

In a manner similar to that used in other studies conducted in the general test anxiety literature (e.g., Putwain et al., 2010), PE performance was assessed through the grade obtained in PE. The PE grade is a combination of the evaluation of three types of skills and abilities that have been developed by students in the sports being evaluated: motor (e.g., performance, technique), methodological (e.g., to define a project adapted to its resources), and social (e.g., to cooperate with a peer) skills and ability. The PE teacher determines him/herself the assessment methods, as there is no national standardized test in France. This grade ranged from 0 to 20 and was the mean of the grades in PE in the first three months of the school year because the questionnaires were completed at the end of November.

\section{Data Analyses}


As illustrated in Figure 1, the FM and PM models were estimated using structural equation modeling (SEM). Both models comprise 12 manifest indicators forming four latent variables (represented as circles) measuring physical self-concept variables (perceived: physical condition, sport competence, physical attractiveness, physical strength; three items for each latent variable), 19 manifest indicators forming five latent variables measuring test anxiety variables (worry, 4 items; self-focus, 3 items; bodily symptoms, 4 items; somatic tension, 4 items; perceived control, 4 items), and one observed variable (represented as a rectangle) measuring grade in physical education. In these models, the physical self-concept variables were all correlated, and the test anxiety variables were all correlated. Given the ordered categorical nature of the indicators measuring the latent variables, the analyses were performed in three steps using the robust weighted least squares (WLSMV) estimator available in Mplus 8.5 (Muthén \& Muthén, 2019). Additionally, in order to take into account the missing responses at the level of the items and the observed variables $(M=1.04 \%)$, the models were estimated based on the full available information using the algorithms implemented in Mplus for WLSMV (Asparouhov \& Muthén, 2010).

In order to control for the nesting of students within schools, we relied on Mplus design-based correction for nesting (TYPE=COMPLEX; Asparouhov, 2005). In the first step, the factor validity and reliability of the nine latent variables were examined using confirmatory factor analyses (CFA). The composite reliability of each latent variable was estimated using McDonald's (1970) omega $(\omega)$. Results from this measurement model were used to generate factor scores (mean of 0 and standard deviation of 1 ) that were used for descriptive statistics and to estimate sex-differences in physical self-concept and test anxiety variables. The factor scores were preferred to observed scale scores, because they preserve the 
characteristics of the measurement model and incorporate a partial correction for measurement errors (Morin et al., 2017; Skrondal \& Laake, 2001). Sex-differences in physical self-concept and test anxiety variables were examined using independent Student $t$ test. For each test the Cohen's $d$ have been estimated. These analyses were performed using IBM SPSS 27 (IBM Corp. Released 2020).

In the second step, the FM models without and with sex and age as control variables were estimated and compared based on their goodness-of-fit. In order to facilitate comparison, sex and age were included in both models. However, in the model without control variables, the regression paths between sex/age and the test anxiety variables and the grade in physical education variable were constrained to be 0 . Additionally, in both of these models, the control (sex and age) variables were correlated with the physical self-concept variables. Based on these analyses, only the best FM model (without or with control variables) was retained for the third step. In the third step, the goodness-of-fit of the best FM model (without or with control variables) was compared with that of the corresponding PM model.

As recommended (e.g., Hu \& Bentler, 1999), the goodness-of-fit of the various models (CFA and SEM) was examined using the chi-square test of exact fit $\left(\chi^{2}\right)$, the comparative fit index $(\mathrm{CFI} \geq .90$ or $>.95)$, the Tucker-Lewis index $(\mathrm{TLI} \geq .90$ or $>.95)$, the root mean square error of approximation (RMSEA $\leq .08$ or $<.06$ ), and the $90 \%$ confidence interval of the RMSEA. Moreover, comparisons of goodness-of-fit between the models were made using $\chi^{2}$ difference tests estimated using the Mplus DIFFTEST function for WLSMV estimation (MD $\Delta \chi^{2}$; Muthén \& Muthén, 2017). The $\chi^{2}$ difference test was complemented (Chen, 2007) by an examination of changes in goodness-of-fit indices ( $\triangle \mathrm{CFI}$ and $\Delta \mathrm{TLI} \geq .01$ and $\triangle \mathrm{RMSEA}$ $\geq .015)$. Finally, the significance of the indirect effects was examined using bias-corrected 
bootstrap (BCB) 95\% confidence intervals (95\% CI), based on 1,000 bootstrap samples (Lau \& Cheung, 2012). An indirect effect is statistically significant when the BCB 95\% CI excludes zero.

\section{Results}

\section{Factor Validity and Reliability of the Latent Variables}

The CFA model comprising the nine latent variables resulted in a satisfactory fit to the data $\left(\chi^{2}=528.31, \mathrm{df}=398, p<.001 ; \mathrm{CFI}=.985, \mathrm{TLI}=.982, \mathrm{RMSEA}=.028 ;\right.$ RMSEA $90 \%$ $\mathrm{CI}=.021-.034)$. As illustrated in Table S1 (see online supplementary file), all loadings were significant and substantial. Additionally, the latent correlations were all significant and showed: (a) negative relationships between physical self-concept and test anxiety (except for perceived control) variables; (b) positive relationships between physical self-concept variables; and (c) negative relationships between test anxiety variables (except for perceived control). Finally, as illustrated in Table S1, the composite reliability coefficients $(\omega)$ of test anxiety and physical self-concept scales were good to excellent $\left(\omega_{\text {range }}=.789-.947\right)$.

\section{Descriptive Statistics, Correlations, and Sex Differences}

Table 1 presents the descriptive statistics and standardized correlations between the nine latent variables and the three observed variables. Findings showed that physical selfconcept variables were correlated with test anxiety, grade in physical education, and sex. Similarly, test anxiety was correlated with grade in physical education and sex (except for bodily symptoms and somatic tension). Finally, age was not correlated with physical selfconcept, test anxiety (except for worry), and sex variables.

Table 2 presents the mean and standard deviation of physical self-concept and test anxiety variables as function of participants' sex and results from independent Student $t$ tests. Results not only showed that boys tended to present significantly higher levels of physical 
self-concept than girls, but also that they tended to present lower scores on test anxiety (except for perceived control) than girls. As illustrated in Table 2, the sizes of these effects were small to large.

\section{Comparison of the Fully and Partially Mediated Models}

Findings from the FM solution not controlled for sex and age resulted in a satisfactory fit to the data $\left(\chi^{2}=614.41, \mathrm{df}=480, p<.001 ; \mathrm{CFI}=.983 ; \mathrm{TLI}=.980 ; \mathrm{RMSEA}=.026\right.$; RMSEA 90\% CI =.019-.032). The inclusion of sex and age as control variables to this model also resulted in a satisfactory level of fit to the data $\left(\chi^{2}=602.97, \mathrm{df}=468, p<.001 ; \mathrm{CFI}=\right.$ $.983 ; \mathrm{TLI}=.980 ; \mathrm{RMSEA}=.026, \mathrm{RMSEA} 90 \% \mathrm{CI}=.020-.032)$. Comparison of both models provided a significant $\chi^{2}$ difference $\left(\mathrm{MD} \Delta \chi^{2}=22.49, \mathrm{df}=12, p=.03\right)$, but fit indices were similar $(\Delta \mathrm{CFI} / \Delta \mathrm{TLI} / \Delta \mathrm{RMSEA}=.000)$. Examination of the unstandardized parameter estimates revealed that regression paths from sex were significant for perceived control, selffocus and worry. More precisely, results showed that boys tended to have significantly higher levels of perceived control $(\mathrm{b}=.305, \mathrm{SE}=.128, p=.017)$ and lower levels of self-focus $(\mathrm{b}=-$ $.304, \mathrm{SE}=.138, p=.027)$ and worry $(\mathrm{b}=-.364, \mathrm{SE}=.152, p=.017)$ than girls. Additional findings also showed that regression paths from age were significant for perceived control, self-focus, worry, and grade in PE. They showed that older adolescents tended to have significantly higher levels of perceived control $(\mathrm{b}=.060, \mathrm{SE}=.028, p=.037)$ and lower levels of self-focus $(\mathrm{b}=-.103, \mathrm{SE}=.042, p=.015)$, worry $(\mathrm{b}=-.118, \mathrm{SE}=.027, p<.001)$ and grade in PE $(b=-.357, \mathrm{SE}=.146, p=.014)$ than younger adolescents. Consequently, based on these findings, the FM model controlled for sex and age was retained as the final model.

The PM model controlling for the effects of sex and age was then examined. This model, adding the direct paths from the physical self-concept variables to the grade in PE, 
resulted in a satisfactory fit to the data $\left(\chi^{2}=597.21, \mathrm{df}=464, p<.001 ; \mathrm{CFI}=.983 ; \mathrm{TLI}=\right.$ $.980 ;$ RMSEA $=.026$; RMSEA 90\% CI $=.020-.032$ ). Comparison of the FM and PM models controlling for the effects of sex and age provided a significant $\chi^{2}$ difference $\left(\operatorname{MD} \Delta \chi^{2}=14.03\right.$, $\mathrm{df}=4, p=.007)$, but fit indices were similar $(\Delta \mathrm{CFI} / \Delta \mathrm{TLI} / \triangle \mathrm{RMSEA}=.000)$. Inspection of the parameter estimates of the direct paths from the PM model revealed that only the direct path between sport competence and grade in PE was significant $(\mathrm{b}=.879, \mathrm{SE}=.264, p=$ .001). Consequently, based on these findings, the PM model controlling for the effects of sex and age was preferred and retained.

Unstandardized coefficients from the regression paths between physical self-concept (Predictors) and test anxiety (Mediators) and grade in PE (Outcome) are presented in Table 3. The other parameters from this model (i.e., correlations between physical self-concept latent variables and controls; correlations between test anxiety latent variables; regression coefficients from paths between control and test anxiety and grade in PE) are presented in Tables S1 to S3 in the online supplementary file. This model accounted for $33.9 \%$ of the variance in adolescents' worry, $26 \%$ of the variance in adolescents' self-focus, $14.2 \%$ of the variance in adolescents' bodily symptoms, $23.6 \%$ of the variance in adolescents' somatic tension, $61.4 \%$ of the variance in adolescents' perceived control, and $40.4 \%$ of the variance in adolescents' grade in PE. More specifically, findings showed that: (a) perceived sport competence significantly and negatively predicted bodily symptoms, somatic tension, and worry; (b) perceived sport competence significantly and positively predicted the grade in PE and perceived control; (c) perceived physical attractiveness significantly and negatively predicted worry and self-focus; (d) perceived physical strength significantly and positively predicted bodily symptoms and somatic tension; (e) bodily symptoms significantly and 
negatively predicted grade in PE, whereas somatic tension and perceived control significantly predicted self-focus, worry, and grade in PE, and positively predicted perceived control; and (g) the adolescents' age significantly and negatively predicted worry and self-focus.

In addition, the present findings revealed a significant indirect effect of: (a) bodily symptoms on the relationships between perceived sport competence and grade in PE $(b=$ $.480, \mathrm{BCB} 95 \% \mathrm{CI}=.065$ to 1.249$)$ and between physical strength and grade in $\mathrm{PE}(\mathrm{b}=-.285$, BCB 95\% CI $=-.713$ to -.040 ); and (b) of somatic tension on the relationship between sport competence and grade in PE ( $b=-.739$, BCB 95\% CI $=-.998$ to -.089$)$. However, the indirect effects of: (a) perceived control on the relationship between sport competence and grade in PE $(\mathrm{b}=.429, \mathrm{BCB} 95 \% \mathrm{CI}=-.542$ to .897$)$ was non-significant; and (b) somatic tension between physical strength and grade in $\mathrm{PE}(\mathrm{b}=.207, \mathrm{BCB} 95 \% \mathrm{CI}=-.013$ to .311$)$ was nonsignificant.

\section{Discussion}

The purposes of the present study were (a) to examine among adolescents the relationships between perceived physical condition, sport competence, physical attractiveness, physical strength, and grade in PE, and (b) to investigate the possible indirect effect of PE test anxiety variables on the relation between physical self-concept variables and grade in PE. The results highlighted direct relationships between different components of physical self-concept and both PE test anxiety and grade in PE, direct relationships between PE test anxiety and grade in PE, and the indirect effect of some components of PE test anxiety between physical self-concept and grade in PE. The results also highlighted that boys had higher levels of physical self-concept and lower scores of test anxiety (except for perceived control) than girls, 
which is in line with the physical self-concept (e.g., Klomsten, Skaalvik, \& Espnes, 2004;

Morin et al., 2018) and PE test anxiety (Danthony et al., 2019; Danthony, Mascret, \& Cury, 2020) studies.

First, the results showed that grade in PE was positively predicted by sport competence. This result was not surprising because relationships between sport competence and objective motor performance have previously been found in middle-school students (Morano, Colella, Robazza, Bortoli, \& Capranica, 2011). Grade in PE was also positively predicted by somatic tension and perceived control, and negatively predicted by bodily symptoms. Similarly to the general anxiety literature in which bodily symptoms were found to be negative predictors of academic performance (e.g., Putwain et al., 2010), bodily symptoms were also found to be negative predictors of performance in PE represented by grade in this school subject. Experiencing troublesome symptoms (e.g., headache, accelerating heart, sweating) tend to decrease grades in PE because of unpleasant feelings before and during examinations. Surprisingly, somatic tension was positively related to grade in PE in the present study, while it was usually not related to academic performance (e.g., Putwain et al., 2010) or negatively related (e.g., McIlroy, 2000). However, somatic tension was found to be related in some studies with positive beliefs (Matthews, Hillyard, \& Campbell, 1999), which could explain the positive predicting role of somatic tension on grade in PE. Finally, grade in PE was positively predicted by perceived control, which is a positive and regulatory dimension of PE test anxiety. This result was in line with recent results showing that perceived control in PE was positively related with adaptive outcomes such as approachbased goals and interest for PE (Danthony et al., 2019). 
Secondly, the results highlighted that some components of the physical self-concept (sport competence, physical attractiveness, and physical strength) were predictors of the five PE test anxiety components. Sport competence was a negative predictor of worry, bodily symptoms, and somatic tension, and a positive predictor of perceived control. Perceived competence in PE has been previously found to be a negative predictor of worry and selffocus, and a positive predictor of perceived control (Danthony et al., 2019), because the likelihood of failure is higher when the situation is considered more threatening. But no relationships were found in Danthony et al.'s study between perceived competence in PE, bodily symptoms, and somatic tension. Assessing perceived sport competence (at the general level), and not specifically perceived competence in PE, led to negative predictions on the affective-physiological dimension of PE test anxiety. Physical attractiveness was also found to negatively predict the two cognitive dimensions of PE test anxiety, namely worry and selffocus. A negative perception of one's appearance in the eyes of others (i.e., the negative perceived attractiveness of one's own body) may induce cognitive responses of anxiety. These responses are negatively toned because they are linked with perceived threats related to body attractiveness before and/or during examinations and tests: fear of failure (Putwain et al., 2010) and fear of others' judgment (Cheng et al., 2009). Finally, physical strength was a positive predictor of bodily symptoms and somatic tension. Feeling physically strong may lead students to be more attentive to body sensations and tensions experienced before and/or during examinations (e.g., feeling tension in his/her muscles, feeling nervous).

Thirdly, the results showed that bodily symptoms have a significant negative indirect effect on the relationships between perceived sport competence and grade in PE, and between physical strength and grade in PE. A significant indirect effect of somatic tension on the 
relationship between sport competence and grade in PE has also been found. Bodily symptoms and somatic tension are self-reported physiological manifestations of test anxiety (e.g., breathing difficulty, headache, feeling nervous, feeling tense) that can be very badly perceived by students and may impair their grade in PE. These physiological indicators of anxiety seem to be of particular relevance in the PE context based on the involvement of the body in different sports (Danthony et al., 2019), which could explain their indirect effects identified in the present study investigating the relationships between physical self-concept and PE grade.

Table 1 showed that the correlations between the test anxiety variables were high. This result was not surprising because worry and self-focus are two kinds of cognitive anxiety and somatic tension and bodily symptoms are two kinds of affective-physiological anxiety. In a more general way, cognitive anxiety and affective-physiological anxiety are two components of test anxiety, which explains the high correlations between worry, self-focus, somatic tension, and bodily symptoms. Moreover, perceived control is a positive component of test anxiety (Mascret et al., 2019) and is consequently negatively correlated with the four previous variables. All these correlations are in line with those found in the general test anxiety literature (e.g., Putwain et al., 2010; Zeidner \& Matthews, 2005) and in the PE test anxiety literature (e.g., Danthony et al., 2019, 2020). Table 1 also showed that the correlations between the physical self-concept variables were positive and high. This is consistent with the initial validation of the hierarchical model of the physical self-perception profile by Fox and Corbin (1989) especially for perceived competence, strength, and physical condition. Moreover, a similar pattern of relationships has been found in Danish schoolchildren 
(Christiansen, Lund-Cramer, Brondeel, Smedegaard, Holt, \& Skovgaard, 2018) and in French obese adolescent school students (Rey, Vallier, Nicol, Mercier, \& Maïano, 2017).

Limitations of the present study and directions for future studies may be envisaged. First, physical self-perceptions and PE test anxiety were self-reported, and such measures can be impacted by social desirability. Secondly, due to the cross-sectional nature of the study design, some reverse relationships between the variables of interest could be expected (e.g., grade as a predictor of test anxiety, grade as a predictor of physical self-perceptions). But the rationale of the present study was based on the test anxiety literature, in which test anxiety is mostly studied as an antecedent of grades (e.g., Putwain et al., 2010). However, PE grades may also influence PE test anxiety in a circular relationship. Concerning the potential reverse relationship between PE grade and physical self-perceptions, some findings in PE showed that gymnastics performance and gymnastics self-concept were reciprocally related across time (Marsh, Chanal, \& Sarrazin, 2006). However, in the test anxiety models, beliefs (and especially competence beliefs) strongly influence the degree and severity of test anxiety and are mostly used as antecedents of test anxiety (Zeidner \& Matthews, 2005). For both of the above reasons, the present study has investigated the relationships between physical selfperceptions, test anxiety, and PE grade in this direction. Thirdly, the questionnaires were completed at the end of November, which explains why the present study considered only the last three months to determine the PE grade. Because PE grade may depend on the nature of the sports practiced by the students, it would have been interesting to average the mean grade over six months or to take into account the annual average grade. Fourthly, the study was conducted in a single country (France), and it would be necessary to carry it out in other countries to potentially generalize the results, because PE curriculum models may be different 
between countries. Finally, Body Mass Index (BMI) was not collected in the present study, while it can impact both students' physical self-perceptions and motor performance (Morano et al., 2011). Future studies should investigate if the pattern of results would be the same between normal- weight, overweight, and obese students.

These findings may also have research and practical implications. The present study follows in the tradition of the test anxiety literature that relates self-perceptions, test anxiety, and academic performance, while investigating it for the first time in the context of PE using specific validated scales (Short Physical Self-Inventory, Revised Test Anxiety and Regulatory dimension of anxiety in PE scale). This study enables us to better understand the processes that link these three variables and to envisage heuristic research perspectives, in particular to study in a more specific way a potential influence of the type of physical activity (e.g., team sports, artistic activities, risky activities) on the relationships that the present study was able to highlight between physical self-perceptions, test anxiety, and PE grades. Implications for practice are also to be discussed. The findings of the present study may be relevant for students to better understand the psychological factors (physical self-perceptions and test anxiety) that may positively or negatively impact their own PE grades. The findings may be useful for PE teachers to identify students at risk in their PE courses (e.g., students with high bodily symptoms, students with a low sport competence) in order to put in place appropriate interventions such as focusing students on task mastery and on their personal progress (Danthony et al., 2020).

\section{Conclusions}

Studying simultaneously physical self-perceptions and test anxiety seemed of interest in the PE context to better explain why some students fail when they are faced with an exam. The results of the present study showed that grade in PE was directly predicted by some components of physical self-perceptions and test anxiety, and that the relationships between 
physical self-perceptions and grade in PE were mediated by bodily symptoms and somatic tension. A better understanding of failure in PE is relevant in the short term to increase the chances of passing a PE exam, but also in the longer term because participation, success, and interest in PE increase the likelihood of the adoption of health-related behaviors by students outside school, such as physical activity and sport participation (Ferriz, González- Cutre, Sicilia, \& Hagger, 2016). 


\section{References}

Arens A. K., Marsh H. W., Craven R. G., Yeung A. S., Randhawa E., Hasselhorn M. (2016). Math self-concept in preschool children: structure, achievement relations, and generalizability across gender. Early Childhood Research Quarterly, 36(3), 391-403. https://doi.org/10.1016/j.ecresq.2015.12.024

Asparouhov, T. (2005). Sampling weights in latent variable modeling. Structural Equation Modeling, 12(3), 411-434. https://doi.org/10.1207/s15328007sem1203_4

Asparouhov, T., \& Muthén, B. O. (2010). Weighted least square estimation with missing data. www.statmodel.com/download/GstrucMissingRevision.pdf

Barkoukis, V., Tsorbatzoudis, H., Grouios, G., \& Rodafinos, A. (2005). The development of a physical education state anxiety scale: A preliminary study. Perceptual and Motor Skills, 100(1), 118-128. https://doi.org/10.2466/PMS.100.1.118-128

Biddle, S., \& Goudas, M. (1994). Sport, activité physique et santé chez l'enfant. Enfance, 47(2), 135-44. https://doi.org/10.3406/enfan.1994.2094

Chanal, J. P., Marsh, H. W., Sarrazin, P. G., \& Bois, J. E. (2005). The big-fish-little-pond effect on gymnastics self-concept: Generalizability of social comparison effects to a physical setting. Journal of Exercise and Sport Psychology, 27(1), 53-70. https://doi.org/10.1123/jsep.27.1.53

Christiansen, L. B., Lund-Cramer, P., Brondeel, R., Smedegaard, S., Holt, A. D., \& Skovgaard, T. (2018). Improving children's physical self-perception through a schoolbased physical activity intervention: The Move for Well-being in School study. Mental Health and Physical Activity, 14, 31-38. https://doi.org/10.1016/j.mhpa.2017.12.005 
Chen, F. F. (2007). Sensitivity of goodness of fit indexes to lack of measurement. Structural Equation Modeling, 14(3), 464-504. https://doi.org/10.1080/10705510701301834

Cheng, W. N. K., Hardy, L., \& Markland, D. (2009). Toward a three-dimensional conceptualization of performance anxiety: Rationale and initial measurement development. Psychology of Sport and Exercise, 10(2), 271-278. https://doi.org/10.1016/j.psychsport.2008.08.001

Choi, N. (2005). Self- efficacy and self- concept as predictors of college students' academic performance. Psychology in the Schools, 42(2), 197-205. https://doi.org/10.1002/pits.20048

Danthony, S., Mascret, N., \& Cury, F. (2019). Development and validation of a scale assessing test anxiety in physical education. Journal of Teaching in Physical Education, 38(4), 357-366. https://doi.org/10.1123/jtpe.2018-0282

Danthony, S., Mascret, N., \& Cury, F. (2020). The relationships between the $3 \times 2$ achievement goal model and test anxiety in Physical Education. European Physical Education Review. https://doi.org/10.1177/1356336X20971325

Dapp, L. C., \& Roebers, C. M. (2019). The mediating role of self-concept between sportsrelated physical activity and mathematical achievement in fourth graders. International Journal of Environmental Research and Public Health, 16(15), 2658. https://doi.org/10.3390/ijerph16152658

Ferriz, R., González- Cutre, D., Sicilia, Á., \& Hagger, M. S. (2016). Predicting healthy and unhealthy behaviors through physical education: A self- determination theory- based longitudinal approach. Scandinavian Journal of Medicine \& Science in Sports, 26(5), 579-592. https://doi.org/10.1111/sms.12470 
Fox, K. R. (2000). Self-esteem, self-perceptions and exercise. International Journal of Sport Psychology, 31(2), 228-240.

Fox, K. R., \& Corbin, C. B. (1989). The physical self-perception profile: Development and preliminary validation. Journal of Sport and Exercise Psychology, 11(4), 408-430. https://doi.org/10.1123/jsep.11.4.408

Hagger, H., Burn, K., Mutton, T., \& Brindley, S. (2008). Practice makes perfect? Learning to learn as a teacher. Oxford Review of Education, 34(2), 159-178.

https://doi.org/10.1080/03054980701614978

Hart, E. A., Leary, M. R., \& Rejeski, W. J. (1989). Tie measurement of social physique anxiety. Journal of Sport and Exercise Psychology, 11(1), 94-104. https://doi.org/10.1123/jsep.11.1.94

Harter, S. (1990). Identity and self-development. In S. Feldman, \& G. Elliot (Eds.): At the threshold: The developing adolescent (pp.352-387). Cambridge, MA: Harvard University Press.

Hu, L., \& Bentler, P. M. (1999). Cutoff criteria for fit indexes in covariance structure analysis. Structural Equation Modeling, 6(1), 1-55. https://doi.org/10.1080/10705519909540118

IBM Corp. Released 2020. IBM SPSS Statistics for Windows, Version 27.0. Armonk, NY: IBM Corp

Khalaila, R. (2015). The relationship between academic self-concept, intrinsic motivation, test anxiety, and academic achievement among nursing students: Mediating and moderating effects. Nurse Education Today, 35(3), 432-438.

https://doi.org/10.1016/j.nedt.2014.11.001 
Klomsten, A. T., Skaalvik, E. M., \& Espnes, G. A. (2004). Physical self-concept and sports: Do gender differences still exist?. Sex roles, 50(1), 119-127. https://doi.org/10.1023/b:sers.0000011077.10040.9a

Lau, R. S., \& Cheung, G. W. (2012). Estimating and comparing specific mediation effects in complex latent variable models. Organizational Research Methods, 15(1), 3-16. https://doi.org/10.1177/1094428110391673

Liukkonen, J., Barkoukis, V., Watt, A., \& Jaakkola, T. (2010). Motivational climate and students' emotional experiences and effort in physical education. The Journal of Educational Research, 103(5), 295-308. https://doi.org/10.1080/00220670903383044

Lohbeck, A., von Keitz, P., Hohmann, A., \& Daseking, M. (2021). Children’s Physical SelfConcept, Motivation, and Physical Performance: Does Physical Self-Concept or Motivation Play a Mediating Role?. Frontiers in Psychology, 12. https://doi.org/10.3389/fpsyg.2021.669936

Maïano, C., Morin, A. J. S., Ninot, G., Monthuy-Blanc, J., Stephan, Y., Florent, J.-F., \& Vallée, P. (2008). A short and very short form of the Physical Self-Inventory for adolescents: Development and factor validity. Psychology of Sport \& Exercise, 9(6), 830-847. https://doi.org/10.1016/j.psychsport.2007.10.003

Marsh, H. W. (2002). A multidimensional physical self-concept: A construct validity approach to theory, measurement and research. Psychology: The Journal of the Hellenic Psychological Society, 9(4), 459-493.

Marsh, H. W. (2006). Self-concept theory, measurement and research into practice: The role of self-concept in educational psychology. London: British Psychological Society. 
Marsh, H. W., Chanal, J. P., \& Sarrazin, P. G. (2006). Self-belief does make a difference: A reciprocal effects model of the causal ordering of physical self-concept and gymnastics performance. Journal of Sports Sciences, 24(1), 101-111. https://doi.org/10.1080/02640410500130920

Marsh, H.W., \& Craven, R.G. (2006). Reciprocal effects of self-concept and performance from a multidimensional perspective. Beyond seductive pleasure and unidimensional perspectives. Perspectives on Psychological Science, 1, 133-163. https://doi.org/10.1111/j.1745- 6916.2006.00010.x

Marsh, H. W., \& Perry, C. (2005). Does a positive self-concept contribute to winning gold medals in elite swimming? The causal ordering of elite athlete self-concept and championship performances. Journal of Sport and Exercise Psychology, 27(1), 71-91. https://doi.org/10.1123/jsep.27.1.71

Marsh, H. W., Trautwein, U., Lüdtke, O., Köller, O., \& Baumert, J. (2006). Integration of multidimensional self- concept and core personality constructs: Construct validation and relations to well- being and achievement. Journal of Personality, 74(2), 403-456. https://doi.org/10.1111/j.1467-6494.2005.00380.x

Mascret, N., Danthony, S., \& Cury, F. (2019). Anxiety during tests and regulatory dimension of anxiety: A five-factor French version of the Revised Test Anxiety scale. Current Psychology. https://doi.org/10.1007/s12144-019-00481-w

Matthews, G., Hillyard, E. J., \& Campbell, S. E. (1999). Metacognition and maladaptive coping as components of test anxiety. Clinical Psychology \& Psychotherapy: An International Journal of Theory \& Practice, 6(2), 111-125. 


\section{https://doi.org/10.1002/(sici)1099-0879(199905)6:2\%3C111::aid-}

\section{cpp192\%3E3.0.co;2-4}

McDonald, R. P. (1970). Theoretical foundations of principal factor analysis, canonical factor analysis, and alpha factor analysis. British Journal of Mathematical and Statistical Psychology, 23(1), 1-21. https://doi.org/10.1111/j.2044-8317.1970.tb00432.x

McIlroy, D. (2000). An evaluation of the factor structure and predictive utility of a test anxiety scale with reference to students' past performance and personality indices. British Journal of Educational Psychology, 70(1), 17-32. https://doi.org/10.1348/000709900157949

Morano, M., Colella, D., Robazza, C., Bortoli, L., \& Capranica, L. (2011). Physical selfperception and motor performance in normal- weight, overweight and obese children. Scandinavian Journal of Medicine \& Science in Sports, 21(3), 465-473. https://doi.org/10.1111/j.1600-0838.2009.01068.x

Morin, A.J.S., Boudrias, J.-S., Marsh, H.W., McInerney, D.M., Dagenais-Desmarais, V., Madore, I., \& Litalien, D. (2017). Complementary variable- and person-centered approaches to the dimensionality of psychometric constructs: Application to psychological wellbeing at work. Journal of Business and Psychology, 32(4), 395-419. https://doi.org/10.1007/s10869-016-9448-7

Morin, A. J. S., \& Maïano, C. (2011). Cross-validation of the short form of the Physical SelfInventory (PSI-S) using exploratory structural equation modeling. Psychology of Sport \& Exercise, 12(5), 540-554. https://doi.org/10.1016/j.psychsport.2011.04.003

Morin, A. J., Maïano, C., Scalas, L. F., Aşçı, F. H., Boughattas, W., Abid, S., ... \& Probst, M. (2018). Cross-cultural validation of the short form of the Physical Self Inventory (PSI- 
S). Sport, Exercise, and Performance Psychology, 7(1), 60-79.

\section{https://doi.org/10.1037/spy0000096}

Muthén, L. K., \& Muthén, B. (2019). Mplus user's guide. Los Angeles, CA: Muthén \& Muthén.

Nieuwenhuys, A., \& Oudejans, R. R. (2017). Anxiety and performance: Perceptual-motor behavior in high-pressure contexts. Current Opinion in Psychology, 16, 28-33. https://doi.org/10.1016/j.copsyc.2017.03.019

Peart, N. D., Marsh, H. W., \& Richards, G. E. (2005). The physical self-description questionnaire: Furthering research linking physical self-concept, physical activity and physical education. Educational Psychology Review, 2(1), 71-77.

Putwain, D. W., Connors, L., \& Symes, W. (2010). Do cognitive distortions mediate the test anxiety-examination performance relationship?. Educational Psychology, 30(1), 1126. https://doi.org/10.1080/01443410903328866

Raufelder, D., \& Ringeisen, T. (2016). Self-Perceived competence and test anxiety. Journal of Individual Differences, 37(3), 159-167. https://doi.org/10.1027/1614-0001/a000202

Rey, O., Vallier, J. M., Nicol, C., Mercier, C. S., \& Maïano, C. (2018). Repeated effects of vigorous interval training in Basketball, Running-Biking, and Boxing on the physical self-perceptions of obese adolescents. Journal of Applied Sport Psychology, 30(1), 6482. https://doi.org/10.1080/10413200.2017.1334159

Skrondal, A., \& Laake, P. (2001). Regression among factor scores. Psychometrika, 66(4), 563-576. https://doi.org/10.1007/bf02296196

Zeidner, M., \& Matthews, G. (2005). Evaluation anxiety. In A. J. Elliot \& C. S. Dweck (Eds.), Handbook of competence and motivation (pp.141-163). London: Guilford Press. 
Zeidner, M., \& Schleyer, E. J. (1999). The big-fish-little-pond effect for academic selfconcept, test anxiety, and school grades in gifted children. Contemporary Educational Psychology, 24(4) 305-329. https://doi.org/10.1006/ceps.1998.0985 


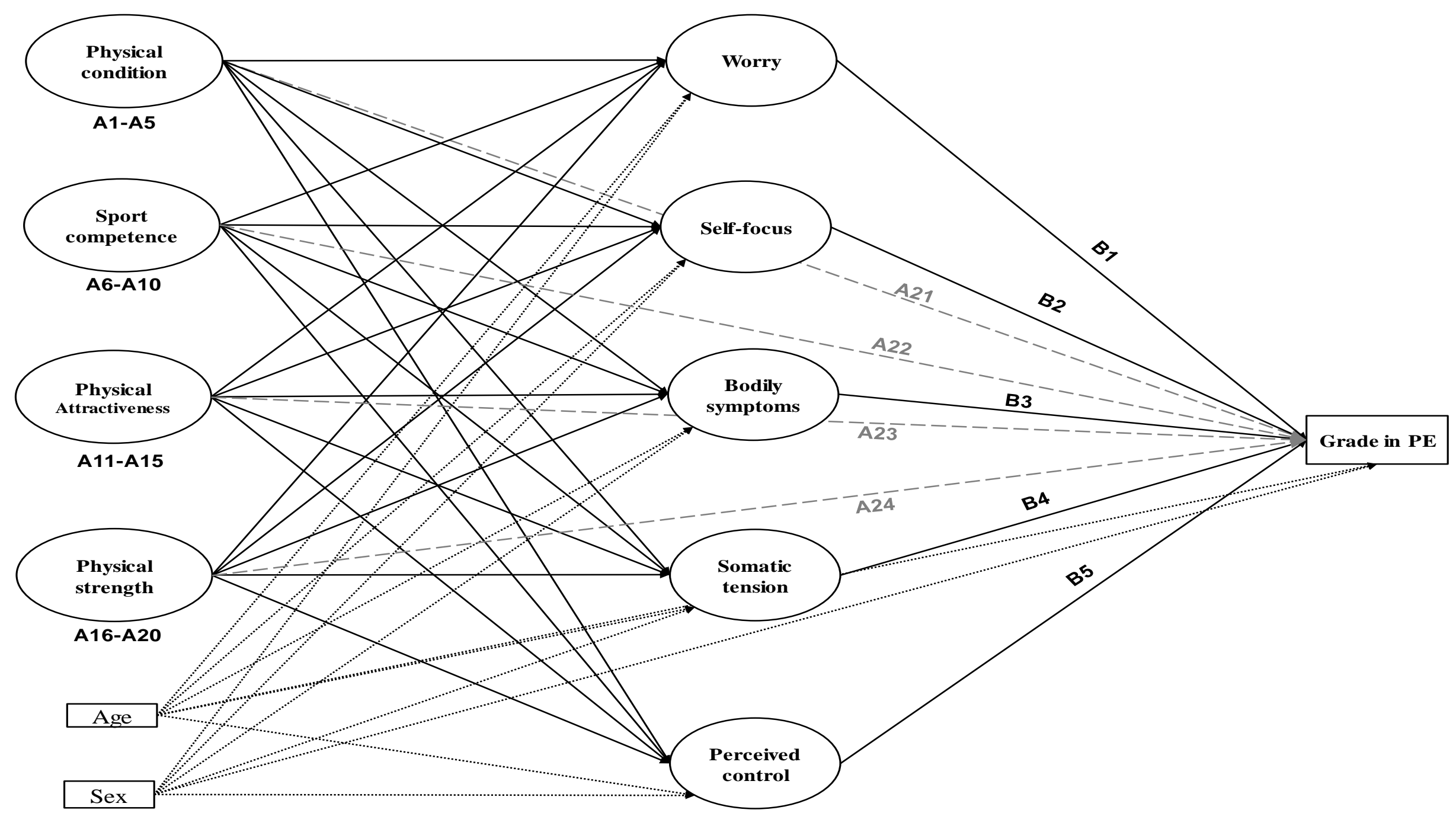

Figure 1. Illustrations of the Hypothesized Fully and Partially Mediated Models Including Sex and Age as Control Variables.

Note $. \mathrm{PE}=$ physical education. In these models, the predictors and the control variables were correlated, and the mediators were correlated. They are not represented in order to simplify the representation of the hypothesized model to the maximum. The full arrows (A1-A20 and B1-B5) reflect a Fully Mediated (FM) model. Partial mediation (PM) will be tested by including the paths depicted through the dashed arrows (A21-A24). Finally, the prediction of controls (sex and age) will be tested by contrasting models including the dotted arrows with models where these paths are constrained to be zero. 


\section{Table 1}

Descriptive Statistics and Standardized Correlations between latent and observed variables

\begin{tabular}{|c|c|c|c|c|c|c|c|c|c|c|c|c|}
\hline Measures & $\begin{array}{l}\text { Physical } \\
\text { condition }\end{array}$ & $\begin{array}{c}\text { Sport } \\
\text { competence }\end{array}$ & $\begin{array}{c}\text { Physical } \\
\text { attractiveness }\end{array}$ & $\begin{array}{l}\text { Physical } \\
\text { strength }\end{array}$ & Worry & $\begin{array}{l}\text { Self- } \\
\text { focus }\end{array}$ & $\begin{array}{c}\text { Bodily } \\
\text { symptoms }\end{array}$ & $\begin{array}{l}\text { Somatic } \\
\text { tension }\end{array}$ & $\begin{array}{l}\text { Perceived } \\
\text { control }\end{array}$ & $\begin{array}{l}\text { Grade } \\
\text { in PE }\end{array}$ & Sex & Age \\
\hline Physical condition & - & & & & & & & & & & & \\
\hline Sport competence & .720 & - & & & & & & & & & & \\
\hline Physical attractiveness & .483 & .601 & - & & & & & & & & & \\
\hline Physical strength & .504 & .708 & .484 & - & & & & & & & & \\
\hline Worry & -.344 & -.519 & -.471 & -.371 & - & & & & & & & \\
\hline Self-focus & -.277 & -.375 & -.468 & -.241 & .735 & - & & & & & & \\
\hline Bodily symptoms & -.229 & -.318 & -.234 & -.097 & .552 & .363 & - & & & & & \\
\hline Somatic tension & -.285 & -.463 & -.305 & -.246 & .706 & .613 & .751 & - & & & & \\
\hline Perceived control & .538 & .775 & .464 & .595 & -.574 & -.424 & -.250 & -.454 & - & & & \\
\hline Grade in PE & .419 & .529 & .385 & .340 & -.453 & -.351 & -.360 & -.315 & .492 & - & & \\
\hline Sex $($ girls $=0 ;$ boys $=1)$ & .438 & .384 & .162 & .358 & -.275 & -.207 & -.103 & -.147 & .373 & .160 & - & \\
\hline Age & -.112 & -.030 & .017 & -.017 & -.097 & -.091 & -.037 & -.001 & .010 & -.022 & -.086 & - \\
\hline Mean & .017 & .000 & -.004 & .006 & .029 & .057 & .053 & .058 & -.009 & 14.62 & - & 13.90 \\
\hline $\mathrm{SD}$ & .899 & .943 & .901 & .905 & .882 & .833 & .821 & .850 & .934 & 2.84 & - & 1.13 \\
\hline Minimum & -1.900 & -2.610 & -2.176 & -2.140 & -2.015 & -1.581 & -1.527 & -1.705 & -2.538 & 4 & - & 12 \\
\hline Maximum & 2.024 & 2.336 & 2.163 & 2.329 & 2.904 & 2.314 & 2.724 & 3.023 & 2.068 & 20 & - & 19 \\
\hline Frequency & - & - & - & - & - & - & - & - & - & - & $\begin{array}{l}54.6 \% \\
\text { girls }\end{array}$ & \\
\hline
\end{tabular}

Notes. PE = physical education; Non-significant correlations are in italics. Other correlations are significant at $p .<.05,<.01$ or $<.001$. Descriptive statistics (mean, SD, minimum and maximum) for measures of physical self-concept and test anxiety are those provided by the factor scores extract from the measurement model. 


\section{Table 2}

Mean and Standard Deviation of Physical Self-Concept and Test Anxiety Variables as Function of Participants' Sex and Results from Independent Student t tests

\begin{tabular}{|c|c|c|c|c|c|c|c|}
\hline \multirow{2}{*}{ Measures } & \multicolumn{2}{|c|}{ Girls } & \multicolumn{2}{|c|}{ Boys } & \multirow{2}{*}{$t(410)$} & \multirow{2}{*}{$p$} & \multirow{2}{*}{$d$} \\
\hline & M & SD & M & SD & & & \\
\hline \multicolumn{8}{|l|}{ Physical Self-Concept } \\
\hline Physical condition & $-.324(2.501)$ & $.743(1.263)$ & $.426(3.835)$ & $.903(1.586)$ & -9.087 & $<.001$ & -.915 \\
\hline Sport competence & $-.337(3.320)$ & $.823(1.237)$ & $.405(4.296)$ & $.921(1.259)$ & -8.548 & $<.001$ & -.855 \\
\hline Physical attractiveness & $-.180(3.293)$ & $.882(1.365)$ & $.208(3.678)$ & $.880(1.306)$ & -4.455 & $<.001$ & -.441 \\
\hline Physical strength & $-.291(2.773)$ & $.846(1.311)$ & $.363(3.711)$ & $.845(1.315)$ & -7.813 & $<.001$ & -.773 \\
\hline \multicolumn{8}{|l|}{ Test anxiety } \\
\hline Worry & $.242(2.353)$ & $.826(0.798)$ & $-.227(1.984)$ & $.880(0.828)$ & 5.573 & $<.001$ & .551 \\
\hline Self-focus & $.205(2.121)$ & $.834(1.025)$ & $-.121(1.755)$ & $.799(0.915)$ & 4.030 & $<.001$ & .399 \\
\hline Bodily symptoms & $.136(1.851)$ & $.784(0.710)$ & $-.046(1.759)$ & $.856(0.711)$ & 2.252 & .025 & .223 \\
\hline Somatic tension & $.210(1.762)$ & $.801(0.737)$ & $-.124(1.578)$ & $.873(0.700)$ & 4.048 & $<.001$ & .401 \\
\hline Perceived control & $-.323(2.645)$ & $.835(0.779)$ & $.369(3.211)$ & $.909(0.767)$ & -8.048 & $<.001$ & -.796 \\
\hline
\end{tabular}


Table 3

Unstandardized Coefficients from the Regression Paths Between Physical Self-Concept (Predictors) and Test Anxiety (Mediators) and Grade in Physical Education (Outcome)

\begin{tabular}{|c|c|c|c|c|c|c|}
\hline Predictors & & Mediators & $\mathrm{b}$ & SE & $\mathrm{b} / \mathrm{SE}$ & $p$ \\
\hline Physical condition (A1) & $\rightarrow$ & Worry & .149 & .099 & 1.505 & .132 \\
\hline Sport competence (A6) & $\rightarrow$ & Worry & -.523 & .137 & -3.816 & .000 \\
\hline Physical attractiveness (A11) & $\rightarrow$ & Worry & -.337 & .083 & -4.067 & .000 \\
\hline Physical strength (A16) & $\rightarrow$ & Worry & .065 & .088 & .746 & .456 \\
\hline Physical condition (A2) & $\rightarrow$ & Self-focus & .067 & .109 & .620 & .535 \\
\hline Sport competence (A7) & $\rightarrow$ & Self-focus & -.244 & .141 & -1.729 & .084 \\
\hline Physical attractiveness (A12) & $\rightarrow$ & Self-focus & -.471 & .077 & -6.116 & .000 \\
\hline Physical strength (A17) & $\rightarrow$ & Self-focus & .142 & .090 & 1.579 & .114 \\
\hline Physical condition (A3) & $\rightarrow$ & Bodily symptoms & .014 & .105 & .130 & .897 \\
\hline Sport competence (A8) & $\rightarrow$ & Bodily symptoms & -.494 & .142 & -3.471 & .001 \\
\hline Physical attractiveness (A13) & $\rightarrow$ & Bodily symptoms & -.101 & .069 & -1.470 & .142 \\
\hline Physical strength (A18) & $\rightarrow$ & Bodily symptoms & .293 & .092 & 3.173 & .002 \\
\hline Physical condition (A4) & $\rightarrow$ & Somatic tension & .129 & .109 & 1.177 & .239 \\
\hline Sport competence (A9) & $\rightarrow$ & Somatic tension & -.714 & .115 & -6.219 & .000 \\
\hline Physical attractiveness (A14) & $\rightarrow$ & Somatic tension & -.077 & .097 & -.795 & .426 \\
\hline Physical strength (A19) & $\rightarrow$ & Somatic tension & .200 & .072 & 2.778 & .005 \\
\hline Physical condition (A5) & $\rightarrow$ & Perceived control & -.108 & .091 & -1.186 & .236 \\
\hline Sport competence (A10) & $\rightarrow$ & Perceived control & 1.175 & .104 & 11.334 & .000 \\
\hline Physical attractiveness (A15) & $\rightarrow$ & Perceived control & .008 & .084 & .098 & .922 \\
\hline Physical strength (A20) & $\rightarrow$ & Perceived control & .121 & .077 & 1.565 & .118 \\
\hline Predictors & & Outcome & $\mathrm{b}$ & SE & $\mathrm{b} / \mathrm{SE}$ & $p$ \\
\hline Physical condition (A21) & $\rightarrow$ & Grade in PE & .243 & .189 & 1.286 & .199 \\
\hline Sport competence (A22) & $\rightarrow$ & Grade in PE & .879 & .264 & 3.333 & .001 \\
\hline Physical attractiveness (A23) & $\rightarrow$ & Grade in PE & -.065 & .258 & -.253 & .801 \\
\hline Physical strength (A24) & $\rightarrow$ & Grade in PE & -.083 & .163 & -.511 & .609 \\
\hline Mediators & & Outcome & $\mathrm{b}$ & SE & $\mathrm{b} / \mathrm{SE}$ & $p$ \\
\hline Worry (B1) & $\rightarrow$ & Grade in PE & -.401 & .227 & -1.763 & .078 \\
\hline Self-focus (B2) & $\rightarrow$ & Grade in PE & -.405 & .224 & -1.808 & .071 \\
\hline Bodily symptoms (B3) & $\rightarrow$ & Grade in PE & -.972 & .304 & -3.194 & .001 \\
\hline Somatic tension (B4) & $\rightarrow$ & Grade in PE & 1.035 & .331 & 3.128 & .002 \\
\hline Perceived control (B5) & $\rightarrow$ & Grade in PE & .365 & .147 & 2.474 & .013 \\
\hline
\end{tabular}

Notes. SE = standard error. Information in parenthesis represent the label of the paths depicted in Figure 1. 


\section{Supplementary Materials for:}

Relationship Between Perceived Physical self-concept and Grade in Physical Education: The Mediating Role of Test Anxiety

Table S1. Standardized Loadings, Uniquenesses, and Latent Correlations

Table S2. Unstandardized Coefficients from the Regression Paths Between Sex/Age and Test Anxiety (Mediators) and Grade in Physical Education (Outcome)

Table S3. Unstandardized Correlations Between Predictors and Control Variables from the Partially Mediated Model Including Sex and Age as Control Variables

Table S4. Unstandardized Correlations Between Mediators from the Partially Mediated Model Including Sex and Age as Control Variables 
Conflict of Interest

the

\author{
(1)
}



The author reports no con

\begin{abstract}
The author reports no conflicts of interest.

\section{Conflict of Interest}

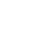


Click here to access/download Supplementary Material Supplementary materials PSE (Revision).docx 